\title{
Basic Research on Parameter Tuning Skills Evaluation Based on Sensor Car Behavior Data in Technology Education
}

\author{
Teruyuki Tamai \\ Graduate School of Humanities and Social Sciences, Hiroshima University / Faculty of Education, Ehime University \\ 3, Bunkyo-cho, Matsuyama, Ehime 790-8577, Japan \\ Yoshihiro Ohnishi \\ Faculty of Education, Ehime University \\ 3, Bunkyo-cho, Matsuyama, Ehime 790-8577, Japan \\ Kazuo Kawada \\ Graduate School of Humanities and Social Sciences, Hiroshima University \\ 1-1-1, Kagamiyama, Higashi-hiroshima, Hiroshima 739-8524, Japan \\ E-mail: tamai.teruyuki.xq@ehime-u.ac.jp,ohnishi@ehime-u.ac.jp,kawada@hiroshima-u.ac.jp \\ www. ehime-u.ac.jp, www. hiroshima-u.ac.jp
}

\begin{abstract}
The "Future Investment Strategy 2018" presented by the Cabinet Office in 2018 states that there is an urgent need to develop human resources who can use AI to achieve the goal of Society 5.0. As a part of this strategy, programming education in primary/secondary level of education is being promoted. However, there are some issues in the quantitative evaluation of learning and teaching methods based on evaluation. In this paper, sensor car teaching materials will be used to teach programming. Then, a new lesson is proposed to tune the optimal parameters by quantitative evaluation. The results of the university students practice of the proposed lesson was explained.
\end{abstract}

Keywords: Junior High School, Parameter Tuning Skill, Quantitative Evaluation

\section{Introduction}

The Cabinet Office published "Future Investment Strategy $2018^{\prime \prime}$ in $2018^{1}$. In this strategy, it states that in the AI era, in addition to the ability to understand and use AI and data with high mathematical capabilities, the ability to set up and solve problems and to create heterogeneous Human resources who can create value with abilities that are difficult to replace by AI, such as the ability to combine things, are needed. AI education at the primary/secondary levels is being strengthened. The development of teaching materials so that programming education can be effectively implemented in elementary schools and the development of local environments so that students can learn more advanced programming are being carried out. Thus, there is an urgent need to improve the education and instruction of programming. This is not limited to Japan, in recent years, there have been many studies on education and lesson in programming. For example, it has been shown that there are many difficulties in learning programming ${ }^{2}$ and that beginners in programming are more likely to learn inclass than in take-home learning ${ }^{3}$. Thus, there is an urgent need to improve human resource development, including programming, both domestically and internationally. In

(C) The 2021 International Conference on Artificial Life and Robotics (ICAROB2021), January 21 to 24, 2021 
Japan, the study of programming at the elementary/secondary level school is mainly conducted in junior high school technology and home economics (in the technology field) (hereinafter referred to as Junior High School Technology). Teaching materials for teaching programming in Junior High School Technology include teaching materials for programming the timing of lights and sounds, and robotics ${ }^{4}$. Programming skills are generally assessed by taking "Can you use sequential, iterative, and conditional processing?" and "Are there typing errors?". There are problems with these types of evaluation, such as the fact that they take a lot of time and depend on the discretion of the teacher. To solve this problem, quantitative evaluation studies have been conducted. The "effect" of the program is visualized by having the learner complete tasks of varying difficulty ${ }^{5}$. This method of evaluation allows students to feel their programming skills improve. On the other hand, in the learning process to develop the competency of Junior High School Technology, it is important to learn how to optimize the solution of problems. There is no practice of learning programming that incorporates quantitative evaluation into this learning process. In this paper, A new evaluation method to quantitatively evaluate a sensor car's linear motion in terms of time and left-right swing during the motion are proposed. Then, A lesson for beginners in programming to develop the skills to tune the optimal parameters are proposed.

\section{Teaching Materials}

In this paper, A sensor car (Made by Artec) as shown in Fig. 1 are used. As a microcontroller board, Studuino mini is used, which is an Arduino-compatible

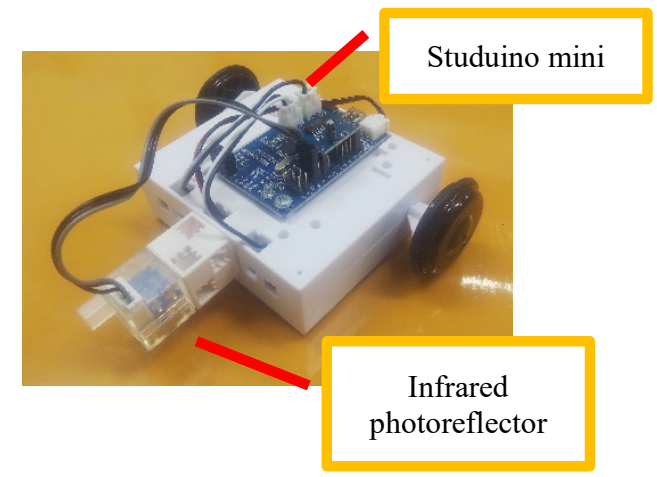

Fig. 1. Sensor car.

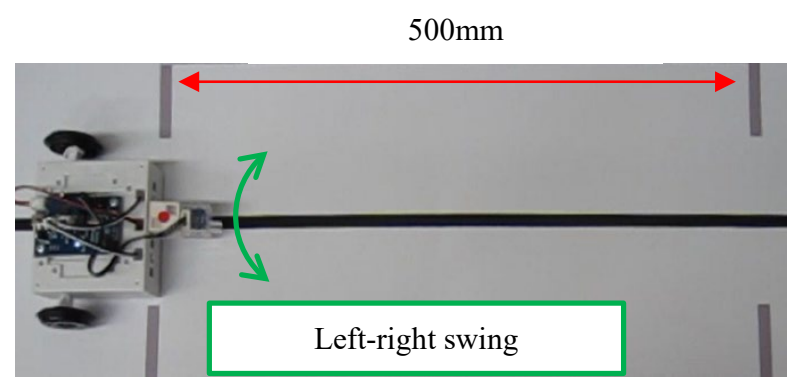

Fig. 2. Field to run.

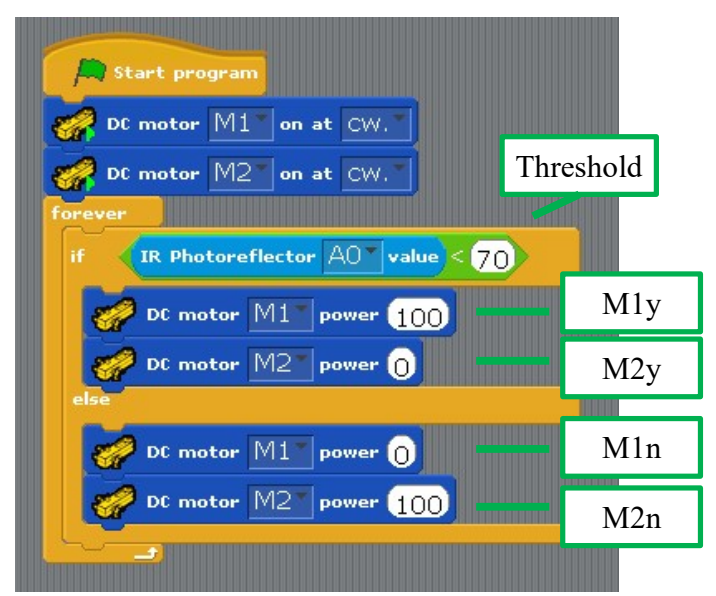

Fig. 3. Studuino mini programming.

microcontroller board with input/output interfaces for education. An infrared photoreflector (RPR-220, Made by ROHM) is used as a sensor to identify the line to be traveled. It was powered by three AA batteries at $4.5 \mathrm{~V}$.

\section{Learning Task}

A learning challenge aimed at the beginning student of programming was devised.

\subsection{Evaluation Items}

As shown in Fig. 2, a black line of $10 \mathrm{~mm}$ width is drawn on the white surface of the field. The sensor car runs straight $500 \mathrm{~mm}$ along the black line in this field. The running time and left-right swing are measured. Then, Task 1 is to shorten the running time. Task 2 is to reduce left-right swing. The learning task was to tune the parameters to solve these two tasks.

(C) The 2021 International Conference on Artificial Life and Robotics (ICAROB2021), January 21 to 24, 2021 


\subsection{Parameters to be tuning}

As shown in Fig. 3, the Studuino mini software is capable of Scratch-based visual programming. The learner tunes five parameters. It is the threshold of the sensor (threshold), and the ratio of PWM to adjust the speed of the left and right motors (M1y, M2y, M1n, M2n).

\section{Parameter Evaluation}

The running time $t$ in Task 1 was measured using a stopwatch. The left-right swing of the sensor car in task 2 was recorded by a digital camera (IXY 92015, Made by CANON). Then, it was analyzed with the video analysis software PV Studio 2D ver2 (Made by L.A.B). To measure the left-right swing, markers were attached at two points as shown in Fig.4. The $\mathrm{x}$-axis and y-axis were defined as shown in Fig. 5, and the position of the marker was read. A left-right swing $y 12$ was calculated by Eq. (1).

$$
y 12=|y 1-y 2|
$$

The variance $\sigma^{2}{ }_{y 12}$ was calculated in Eq. (2). However, $\mathrm{n}$ is the number of data extracted from the video from the start to the goal by the video analysis software. This $\sigma^{2}{ }_{y 12}$ was used as the left-right swing.

$$
\sigma_{y 12}^{2}=\frac{\sum_{i=1}^{n}\left(y 12_{i}-\overline{y 12}\right)^{2}}{n}
$$

If the running time $t$ and the degree of left-right swing $\sigma^{2}{ }_{y 12}$ become small, the learner is able to choose a good parameter. In other words, the parameter tuning skill is high.

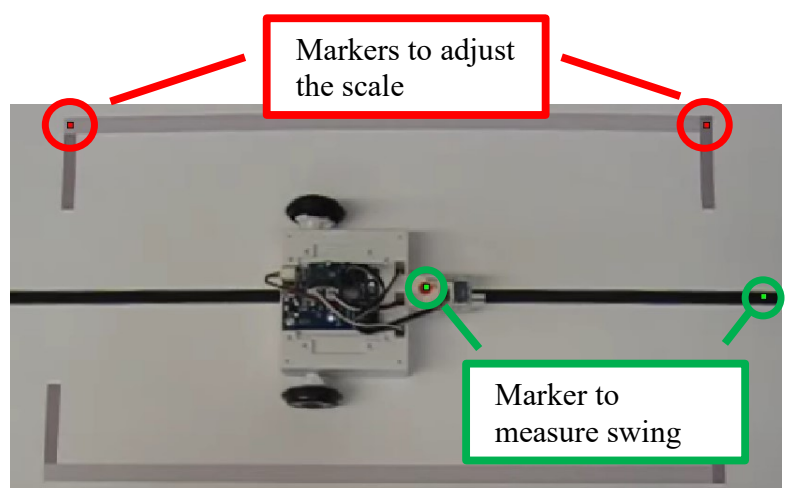

Fig. 4. Marker position.

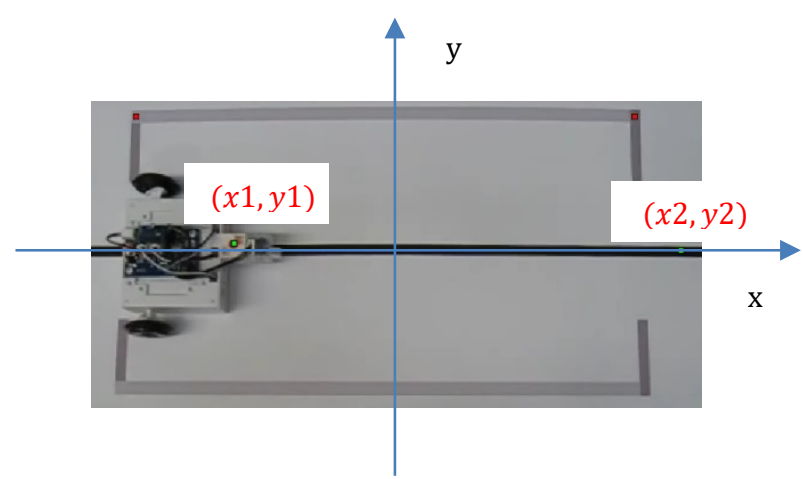

Fig. 5 Set axis.

Table 1. Lesson plan.

\begin{tabular}{|c|c|l|}
\hline & $\begin{array}{c}\text { Hours } \\
{[\mathrm{min}]}\end{array}$ & \multicolumn{1}{|c|}{ Main learning contents } \\
\hline Lesson 1 & 60 & $\begin{array}{l}\text { Check the relationship between } \\
\text { the adjustment of parameters } \\
\text { and the movement of the } \\
\text { sensor car's wheels. }\end{array}$ \\
\hline Lesson 2 & 30 & $\begin{array}{l}\text { Know how to program a line } \\
\text { trace using a sensor car. }\end{array}$ \\
\hline Lesson 3 & 90 & $\begin{array}{l}\text { Understand the learning task. } \\
\text { Tuning the optimal parameters. }\end{array}$ \\
\hline
\end{tabular}

\section{Lesson Suggestions}

To examine the time required to implement the proposed learning evaluation method and the learning effects, a class was practiced by university students in teacher training. Two people could use one sensor car. eight groups of 16 people were conducted. Table 1 shows the learning plan.

In Lesson 1, students experienced how changing the direction and speed of rotation from left to right changed the behavior of the sensor car. The reason for this was that most of the students had never experienced programming a sensor car before. In Lesson 2, students were shown the program shown in Fig. 3 and were taught the steps of the program to do a line trace. In Lesson 3, the students first predicted the movement of the sensor car and designed the parameters to complete the task. Then, they programmed the sensor car according to the design and made it work. In this way, Lesson 3 incorporated the cycle of design, creation, evaluation, and improvement so that the solution to the problem 
Table 2. Sensor car results.

\begin{tabular}{|l||c|c|c|c|c|c|c||c|c|c|c|c|c|c|}
\hline \multicolumn{1}{|c||}{} & \multicolumn{9}{c||}{ Group 1 } & \multicolumn{6}{c|}{ Group 2 } \\
\hline & $\mathrm{t}[\mathrm{s}]$ & $\sigma^{2}{ }_{12}$ & $\begin{array}{c}\text { thresh } \\
\text { old }\end{array}$ & M1y & M2y & M1n & M2n & $\mathrm{t}[\mathrm{s}]$ & $\sigma^{2}{ }_{12}$ & $\begin{array}{c}\text { thresh } \\
\text { old }\end{array}$ & M1y & M2y & M2n & M1n \\
\hline \hline $\begin{array}{l}\text { First } \\
\text { time }\end{array}$ & 4.17 & 0.085 & 80 & 55 & 100 & 100 & 55 & 4.01 & 0.32 & 46 & 100 & 20 & 20 & 100 \\
\hline $\begin{array}{l}\text { Secon } \\
\text { d time }\end{array}$ & 4.12 & 37.80 & 60 & 75 & 100 & 100 & 75 & 4.05 & 0.31 & 45 & 100 & 30 & 30 & 100 \\
\hline $\begin{array}{l}\text { Third } \\
\text { time }\end{array}$ & 4.02 & 0.24 & 60 & 80 & 100 & 100 & 60 & 3.73 & 0.25 & 43 & 100 & 80 & 80 & 100 \\
\hline $\begin{array}{l}\text { Fourth } \\
\text { time }\end{array}$ & 3.98 & 0.18 & 60 & 90 & 100 & 100 & 75 & 3.73 & 0.16 & 43 & 100 & 90 & 90 & 100 \\
\hline
\end{tabular}

would be optimal, which is considered important in the learning process.

\section{Results and Discussion}

Table 2 shows the results of the practice of the university students. In the practice of this study, university students carried out the learning process of Lesson 3 four times. Some of the results of the students' practice are shown in Table 2. For Group 1, the fourth time was the fastest for Task 1. And for Task 2, the second time was the worst. However, it was improved in the third and fourth times. For Group 2, for the third and fourth times is the same for Task 1. However, the left-right swing was improved from 0.25 to 0.16 . For this value, the difference in variance was determined by the $\mathrm{F}$ test. Assuming that the left-right swing of the sensor car is normally distributed, a onetailed test with 114,114 degrees of freedom was performed and the $\mathrm{F}$ value was 0.0070 . Therefore, it can be said that there is a significant difference at $5 \%$ level of significance. For the groups shown here, it was concluded from the quantitative evaluation that the parameters were better regulated.

\section{Conclusion}

In this study, a lesson and an evaluation method were proposed to develop the skills to tune parameters. The proposed lesson and evaluation method were practiced by university students. It was shown that the parameter regulation skills could be evaluated quantitatively. The evaluated data were compared and statistically processed. And the goodness of parameter tuning was demonstrated. In future studies, learning time will be organized and supplementary materials will be developed so that this study can be implemented in junior high schools.

\section{Acknowledgements}

The authors are also grateful that this work was supported by the Ehime University Challenge Support Fund.

\section{References}

1. Cabinet Office, Future Investment Strategy 2018, 2018. http://www.kantei.go.jp/jp/singi/keizaisaisei/pdf/miraitou si2018_en2.pdf

[Accessed December 10, 2020]

2. Y. Bosse and M. A. Gerosa, Why is programming so difficult to learn? Patterns of Difficulties Related to Programming Learning, ACM SIGSOFT Software Engineering Notes, 41(6) 2016, pp.1-6

3. O. Karnalim, Comparing the Impact of Programming Assessmennt Type:In-Class Vs Take-Home, iJEP, 10(4) 2020, pp.125-132

4. Y. Ohnishi, K. Honda, R. Nishioka, S. Mori and K. Kawada, Robotics Programming Learning for Elementary and Junior High School Student, Journal of Robotics and Mechatronics, 29(6) 2017, pp. 992-998

5. Y. Ohnishi, T. Tamai and K. Kawada, Estimation of Programming Learning Achievement by Line Tracing Robot, Proceedings of the 2019 International Conference on Artificial Life and Robotics, Beppu, Oita, Japan, Feb. 2019, pp. 431-434 